\title{
AÇÕES COLETIVAS E JUSTICIABILIDADE DOS DIREITOS FUNDAMENTAIS SOCIAIS
}

\author{
JOSÉ MARIA ROSA TESHEINER ${ }^{*}$
}

\begin{abstract}
RESUMO: Faz-se distinção entre tutela de direitos coletivos e tutela coletiva de direitos individuais, tendo em vista suas diferentes finalidades (aplicação do Direito objetivo e tutela de direitos subjetivos). Ações individuais relativas a direitos sociais têm limites fixados por lei ou por ações coletivas relativas a direitos difusos ou coletivos stricto sensu. PALAVRAS-CHAVE: Direitos Sociais. Ações Coletivas. Políticas Públicas.
\end{abstract}

ABSTRACT: The distinction between class actions related to collective rights and class actions related to homogeneous individual rights is set in regards to their different goals: the enforcement of Law and the protection of individual rights. Individual actions related to social rights have limits established by law or by actions related to diffuse or collective rights. KEYWORDS: Social Rights. Class Actions. Policies.

SUMÁRIO: Introdução; 1. Ponto de partida; 2. Titularidade dos direitos sociais; 3. Limites das ações individuais relativas a direitos sociais; Conclusão; Referências.

SUMMARY: Introduction; 1. Starting point; 2. Social rights ownership; 3. Limits of individual actions related to social rights; Conclusion; References.

\section{INTRODUÇÃO}

Apresento, aqui, algumas reflexões sobre a justiciabilidade dos direitos fundamentais sociais, em conexão com a diferença entre a tutela de direitos coletivos e a tutela coletiva de direitos fundamentais, tendo em vista suas diferentes finalidades, a primeira visando à aplicação (às vezes, à criação) do Direito objetivo; a segunda, à tutela de direitos subjetivos.

\section{PONTO DE PARTIDA}

Ponto de partida e roteiro é o artigo de Liana Cirne Lins, intitulado "A tutela inibitória coletiva das omissões administrativas: um enfoque processual sobre a justiciabilidade dos direitos sociais. ${ }^{1}$

Artigo recebido em 13.01.2010 - Elaboração dos Pareceres em 18.06.2010 e 24.06.2010.

Aprovado para publicação pelo Conselho Editorial em 07.07.2010.

* Professor da PUCRS, Porto Alegre/RS. Desembargador aposentado do Estado do Rio Grande do Sul.

${ }^{1}$ LINS, Liana Cirne. A Tutela Inibitória Coletiva das Omissões Administrativas: um enfoque processual sobre a justiciabilidade dos direitos fundamentais sociais. Artigo publicado na Revista Direito do Estado $\mathrm{n}^{\circ} 12$, Rio de Janeiro: Renovar/Instituto Idéias, out-dez 2008, p. 223-261.

http://74.125.93.132/search?q=cache:12lWnVZ_Kt0J:www.stf.jus.br/arquivo/cms/processoAudienciaPublica Saude/anexo/Direitos_sociais_processo.pdf+LIANA+CIRNE+LINS+A+TUTELA+INIBIT\%C3\%93RIA+ COLETIVA\&cd=1\&hl=pt-BR\&ct=clnk\&gl=br Acesso em 4. jan. 2009. 
A Autora desenvolve o tema em nove tópicos, a saber:

1. Um enfoque processual sobre a justiciabilidade dos direitos fundamentais sociais.

2. A co-titularidade social dos direitos fundamentais sociais: crítica à categoria de direito subjetivo como fundamento à sua justiciabilidade.

3. A prevalência da tutela coletiva dos direitos fundamentais sociais: proposta lege lata de hierarquização das tutelas.

4. A tutela coletiva e a justiciabilidade da dimensão objetiva dos direitos fundamentais.

5. O artigo $7^{\circ}$ da Lei da Ação Civil: o papel do juiz na observância da hierarquização das tutelas dos direitos fundamentais sociais.

6. O controle judicial das omissões administrativas: pode o Judiciário determinar gastos à Administração?

7. A tutela inibitória: sua pertinência para a justiciabilidade dos direitos fundamentais sociais.

8. Como convencer a Administração-ré a adimplir a omissão administrativa?

9. Justiciabilidade dos direitos sociais e poder discricionário: o pedido alternativo como instrumento de equilíbrio entre Político e Jurídico.

Limito-me ao exame dos dois primeiros, que dizem respeito à relação entre os direitos difusos e coletivos stricto sensu, e os direitos individuais, sejam ou não tratados coletivamente.

Esclareço, desde logo, que estou a interpretar o pensamento da Autora com minhas próprias categorias, que divergem num ponto fundamental: na exposição da Autora, direitos difusos, coletivos stricto sensu e individuais homogêneos são todos direitos coletivos; de minha parte, seguindo lição de Zavascki, considero inarredável a distinção entre direitos coletivos (difusos e coletivos stricto sensu) e direitos individuais homogêneos, que são direitos individuais, mesmo quando tratados coletivamente.

Diz Zavascki:

É preciso, pois, que não se confunda defesa de direitos coletivos com defesa coletiva de direitos (individuais). Direitos coletivos são direitos subjetivamente transindividuais (= sem titular determinado) e materialmente indivisíveis. Os direitos coletivos comportam sua acepção no singular, inclusive para fins de tutela jurisdicional. Ou seja: embora indivisível, é possível conceber-se uma única unidade da espécie de direito coletivo. O que é múltipla (e indeterminada) é a sua titularidade, e daí a sua transindividualidade. "Direito coletivo” é designação genérica para as duas modalidades de direitos transindividuais: o difuso e o coletivo stricto sensu. É denominação que se atribui a uma especial categoria de direito material, nascida da superação, hoje indiscutível da tradicional dicotomia entre interesse público e interesse privado. É direito que não pertence à administração pública e nem a indivíduos particularmente determinados. Pertence, sim, a um grupo de pessoas, a uma classe, a uma categoria, ou à própria sociedade, considerada em seu sentido amplo. Na definição de Péricles Prade, “... são os titularizados por uma cadeia abstrata de pessoas, ligadas por vínculos 
fáticos exsurgidos de alguma circunstancial identidade de situação, passíveis de lesões disseminadas entre todos os titulares, de forma pouco circunscrita e num quadro abrangente de conflituosidade.

Já os direitos individuais homogêneos são, simplesmente, direitos subjetivos individuais. A qualificação de homogêneos não altera e nem pode desvirtuar essa sua natureza. É qualificativo utilizado para identificar um conjunto de direitos subjetivos individuais ligados entre si por uma relação de afinidade, de semelhança, de homogeneidade, o que permite a defesa coletiva de todos eles. Para fins de tutela jurisdicional coletiva, não faz sentido, portanto, sua versão singular (um único direito homogêneo), já que a marca da homogeneidade supõe, necessariamente, uma relação de referência com outros direitos individuais assemelhados. Há, é certo, nessa compreensão, uma pluralidade de titularidades, como ocorre nos direitos transindividuais; porém, diferentemente desses (que são indivisíveis e seus titulares são indeterminados), a pluralidade, nos direitos individuais homogêneos, não é somente dos sujeitos (que são determinados), mas também do objeto material, que é divisível e pode ser decomposto em unidades autônomas, com titularidade própria. Não se trata, pois, de uma nova espécie de direito material. Os direitos individuais homogêneos são, em verdade, aqueles mesmos direitos comuns ou afins de que trata o art. 46 do CPC (nomeadamente em seus incisos II e IV), cuja coletivização tem um sentido meramente instrumental, como estratégia para permitir sua mais efetiva tutela em juízo. Em outras palavras, os direitos homogêneos "são, por esta via exclusivamente pragmática, transformados em estruturas moleculares, não como fruto de uma indivisibilidade inerente ou natural (interesses de direitos públicos e difusos) ou da organização ou existência de uma relação jurídica-base (interesses coletivos stricto sensu), mas por razões de facilitação de acesso à justiça, pela priorização da eficiência e da economia processuais (...). Quando se fala, pois, em "defesa coletiva” ou em "tutela coletiva” de direitos homogêneos, o que se está qualificando como coletivo não é o direito material tutelado, mas sim o modo de tutelá-lo, o instrumento de sua defesa. ${ }^{2}$

É certo que de um mesmo fato podem decorrer ações para a tutela de direitos difusos, bem como para a tutela de direitos individuais, sejam ou não homogêneos. Um exemplo simples é o da propaganda enganosa, que pode gerar uma ação coletiva apenas para que cesse; uma ação coletiva em prol dos que foram por ela efetivamente enganados e prejudicados e, ainda, ações individuais de ressarcimento. Outro exemplo é o de ação civil pública proposta em prol de uma coletividade, para impedir a exalação de produtos tóxicos, que não impede ação individual, fundada no direito de vizinhança.

É preciso insistir, porém, em que as ações relativas a direitos difusos não se confundem com as relativas a direitos individuais homogêneos.

Pode-se distingui-las, dizendo-se que aquelas visam preponderantemente à aplicação do Direito objetivo; estas, à tutela de direitos individuais.

Nada se ganha ao se pensar numa ação civil pública, proposta em defesa do meio ambiente, como proposta por um "substituto processual", em defesa de "direitos"

${ }^{2}$ ZAVASCKI, Teori Albino. Processo Coletivo - Tutela de Direitos Coletivos e Tutela Coletiva de Direitos. São Paulo: Revista dos Tribunais, 2006. p. 41-3. 
de pessoas indeterminadas. Ao se propor uma ação para impedir a queima de uma floresta, nada mais se intenta do que aplicar o Direito objetivo, que veda essa prática. Não se trata de ação proposta por um "substituto processual", em defesa de "direitos" de pessoas indeterminadas, mas de exercício de função pública. No exemplo, os beneficiados pela ação não precisam necessariamente ser pessoas. Podem ser os animais da floresta. Podem ser as gerações futuras. ${ }^{3}$

Nas ações relativas a direitos difusos não há substituição processual, pela simples razão de que não há substituídos. Para explicá-las, não se precisa pensar em subjetivação de direitos. Trata-se de aplicar o Direito objetivo.

Há casos em que se pode negar a própria existência de grupo, como, por exemplo, na ação proposta pelo Ministério Público contra o Município de São Leopoldo, para anular lei autorizadora de permissão de uso de área verde a uma associação de moradores. ${ }^{4}$ Se grupo houvesse, seria no lado passivo, e formado pelos moradores individualmente beneficiados pela permissão, de cuja citação nem sequer se cogitou.

A inexistência de grupo fez-se evidente também na ação civil pública proposta pelo Ministério Público para suspender a implantação do Condomínio "Reserva do Lago” até a obtenção de Licença de Operação pela Fundação Estadual de Proteção Ambiental (FEPAM), sob pena de multa diária de R\$5.000,00. ${ }^{5}$

\footnotetext{
${ }^{3}$ Em verdade, a teconociência tem conferido aos homens poderes cada vez maiores. Seu totalitarismo põe em risco o mundo natural e a humanidade inteira. O que o poder apocalíptico da tecnociência põe em jogo, além da sobrevivência física da espécie humana, é também a integridade da sua essência. De fato, o progresso cientifico transformou-se numa espécie de "Prometeu definitivamente desacorrentado", solto, colocando em xeque as condições globais da vida humana, o futuro da espécie e da natureza como um todo.
}

A ética tradicional preocupava-se com o melhor ser possível do homem, ou seja, as virtudes, como a honradez, o respeito, a justiça, a caridade. Estas, entretanto, resultaram eclipsadas pelo crescente alcance do obrar coletivo. Nenhuma ética anterior teve de cuidar das condições globais da vida humana nem do futuro remoto, e ainda menos da própria extinção da espécie. Por isso também nenhuma ética ou metafísica anterior proporciona os princípios para enfrentar as novas questões, muito menos é portadora de uma doutrina já pronta para essa finalidade.

Isso, entretanto, não implicar perder de vista as antigas normas éticas, as velhas virtudes cardeais. Não se trata, pois de substituir uma ética por outra, mas de 'adicionar ao catálogo de obrigações... outras novas, que nunca foram consideradas, porque não havia ocasião para isso’.

Volta-se à questão leibniziana: porque o ser e não o nada? Por que se deve preferir o ser ao nada? Esta pergunta, agora é feita com mais urgência do ponto de vista ético: deve haver humanidade? Porque deve haver? Por que se tem de respeitar a herança genética e conservar o ser humano tal como a evolução o produziu? Enfim, por que deve prevalecer a vida? É que o ser vale mais do que o não ser; há 'preferência absoluta do ser sobre o nada'.

As gerações futuras, todavia, nada farão a favor do homem presente. Disso emerge o elemento característico do imperativo, a não-reciprocidade. A obrigação de um (homem do presente) não é a imagem inversa do dever do outro (homem do futuro). Desse tipo é precisamente a obrigação parental, a dos pais em relação aos filhos, à qual também se assemelha a responsabilidade do homem de Estado. Ambas estas responsabilidades envolvem o ser total do objeto, são contínuas e se referem ao futuro. (NEDEL, José. A ética da responsabilidade de Hans Jonas. Revista da Ajuris, Porto Alegre, (82): t. I, p. 128-42, junho/2001).

${ }^{4}$ TJRGS, $3{ }^{a}$ Câmara Cível, Apelação Cível 70020552246, Nelson Monteiro Pacheco, relator, J. 4.06.2009.

${ }^{5}$ TJRGS, $21^{\text {a }}$ Câm. Cível, Apelação Cível 70029714060, Francisco José Moesch, relator, J. 3.06.2009. 
Não se pode, porém, afirmar a inexistência de grupo, em qualquer caso de ação relativa a direitos difusos. Considere-se, por exemplo, a ação civil pública proposta pelo Ministério Público contra Maria Marques Isbarrola, julgada procedente em parte, para limitar a criação de animais domésticos, ${ }^{6}$ ação, aliás, provocada pelos vizinhos, diretamente interessados na limitação.

Nas ações relativas a direitos individuais homogêneos há substituição processual, havendo, em um dos pólos da relação processual, um substituto processual, agindo em nome próprio, em defesa de direitos individuais dos substituídos, que não estão presentes no processo e podem até ser proibidos de nele intervir. Há um grupo integrado por indivíduos determinados ou indetermináveis. Trata-se, claramente, de tutela de direitos individuais. Sirva de exemplo a ação proposta pelo Diretório Central dos Estudantes da Universidade Federal do Rio Grande do Sul, para a concessão do benefício da “meia entrada” para estudantes, como previsto na Lei Municipal 9.989/2006. ${ }^{7}$

\section{TITULARIDADE DOS DIREITOS SOCIAIS}

Observa Liana Cirne Lins que os serviços públicos caracterizadores dos direitos sociais foram formulados, não para serem desfrutados isoladamente, mas por toda a coletividade, e não pela lógica da exclusão, mas pela da inclusão. Foram desenvolvidos para atender toda coletividade, respeitando-se os princípios que norteiam o atendimento aos serviços públicos, vale dizer, universalidade e impessoalidade.

A regra, pois, é a de que a titularidade dos direitos sociais é efetivamente social, razão pela qual se impõe sua proteção na forma social - vale dizer, de forma difusa ou coletiva stricto sensu, ainda que sem exclusão da possibilidade, residual, de proteção individual.

É residual essa proteção individual, porque se quer dar prevalência à tutela coletiva. É que a tutela individual, sem limitações, tem potencial para anular a coletiva.

Descendo das abstrações para o real concreto, diz a Autora:

É de ser dividida a preocupação de José Reinaldo de Lima Lopes: "Não existindo escolas, hospitais e serviços capazes e em número suficiente para prestar o serviço o que fazer?

Prestá-lo a quem tiver a sorte de obter uma decisão judicial $e$ abandonar a imensa maioria à fila de espera? Seria isto viável de fato e de direito, se o serviço público deve pautar-se pela sua universalidade, impessoalidade e pelo atendimento a quem dele mais precisar e cronologicamente anteceder os outros? Começam, pois, a surgir dificuldades enormes quando se trata de defender com instrumentos individuais um direito social”.

Diz mais:

... a errônea compreensão individualista que se faz dos direitos sociais implica a virada da natureza dos mesmos ao avesso, tornando-os mais um

\footnotetext{
${ }^{6}$ TJRGS, $33^{\text {a }}$ Câmara Cível, Apelação Cível 70025515628, Nelson Monteiro Pacheco, relator, J. 28.05.2009.

${ }^{7}$ TJRGS, $9^{\text {a }}$ Câmara Cível, Agravo de Instrumento 70029970928, Odone Sanguiné, relator, J. 28.05.2009.
} 
direito exclusivista que se dá, literalmente, em detrimento dos demais que não tiveram a mesma sorte de obter uma decisão favorável.

À toda evidência, o impacto de decisões judiciais de cunho individual traz implicações porventura significativas para a destinação dos recursos orçamentários, que facilmente se vê descontextualizada das políticas públicas de saúde. Isto não deixa de ser preocupante e merece ser ponderado, mormente quando é sabida a influência da estratificação social em políticas públicas de saúde - destacando-se as estratificações pela moradia, etnia, ocupação, habitação, escolaridade, renda e desemprego - que impõe, como adverte Peces-Barba, uma visão sistemática e geral não só dos custos, mas igualmente dos potenciais afetados pelo benefício.

\section{Prossegue a Autora:}

A propósito, Luís Roberto Barroso, ao se referir às decisões judiciais determinando entrega de medicamentos fora da listagem elaborada pelos entes federativos para dispensa de medicamentos, afirma que "Tais decisões privariam a Administração da capacidade de se planejar, comprometendo a eficiência administrativa no atendimento ao cidadão. Cada uma das decisões pode atender às necessidades imediatas do jurisdicionado, mas, globalmente, impediria a otimização das possibilidades estatais no que toca à promoção da saúde pública”.

Observo que a expressão "direitos difusos” é imprópria, porque se refere a direitos que são de todos e, portanto, não são de ninguém. A ideia de "direitos subjetivos" só tem sentido como atribuição a alguns e não a todos, o que é especialmente visível no direito de propriedade, que não é senão o direito de excluir os demais daquilo que é meu. Direitos subjetivos são parcelas ou partes que perdem sentido quando se integram no todo. Ações visando à tutela de “direitos difusos” são ações que visam à aplicação do Direito objetivo.

Liana Cirne Lins continua:

Se se pensar numa classificação das normas de direitos sociais dentro de um binômio, qual seja, direitos subjetivos exigíveis versus simples imposições constitucionais que não geram exigibilidade, rapidamente se concluirá aqui pela primeira opção, a de que os direitos sociais geram direito subjetivo e são exigíveis.

\section{Observa:}

Parece que, motivada por imprimir juridicidade - e conseqüentemente eficácia aos direitos sociais - a melhor doutrina buscou adequá-los ao referencial conhecido e apto a significar que aquele direito não cairia no vazio, no mero simbolismo, e este referencial foi justamente o de direito subjetivo. Entretanto, a tradução da exigibilidade dos direitos sociais em direitos subjetivos opera, afinal, uma armadilha: a do tradicional sujeito de direito, isolado e atomizado, que o Estado Social superou.

Reduzir os direitos sociais a direitos subjetivos - ainda que pela bem intencionada disposição de imprimir-lhes eficácia - só pode ter por resultado 
exatamente o oposto, ou seja, a redução da sua esfera de eficácia, uma vez que os direitos sociais não se enquadram, em regra, aos esquemas dos tradicionais direitos individuais e subjetivos.

Prossegue dizendo que não se deve buscar similitude ou homegeneidade entre os direitos sociais e os individuais, mas reconhecer sua diferença, sua especificidade, sem com isso lhes negar sua juridicidade própria e sua exigibilidade específica. Sua titularidade é social, o que prefiro traduzir pela expressão "Direito objetivo", que mais fortemente nega a ideia de subjetivação.

\section{LIMITES DAS AÇÕES INDIVIDUAIS RELATIVAS A DIREITOS} SOCIAIS

Segundo a Autora, a titularidade social dos direitos sociais não exclui a titularidade individual, "sendo esta, porém, meramente residual”.

Concordo com a Autora, porém, com outro enfoque. Dizem respeito aos chamados direitos sociais as ações relativas a direitos difusos ou coletivos stricto sensu. Dizem respeito a direitos individuais as ações coletivas relativas a direitos individuais homogêneos e, é claro, também ações individuais, necessariamente relacionadas a direitos individuais.

O problema está na coordenação entre essas duas espécies de ações, de modo que uma não anule a outra.

Faz-se essa coordenação, segundo a Autora, a partir de ideia de co-titularidade dos direitos sociais e do caráter residual dos direitos sociais, limitados estes ao "mínimo existencial”. Em outras palavras, o que se pode assegurar, em ação individual relativa aos chamados direitos sociais, é tão só o "mínimo existencial”. Não há, além desse mínimo, direito subjetivo e qualquer "plus” somente pode ser objeto de ação coletiva que, em nosso sistema, não pode ser proposta senão pelos legitimados indicados por lei.

Diz Liana Cirne Lins que a errônea compreensão da titularidade dos direitos sociais tem significativas consequências práticas, além das teóricas, tal como o impacto de uma decisão judicial isolada sobre um serviço público de caráter social. Estabelece uma lógica de exclusão (a realização do direito social de um indivíduo em detrimento dos demais) e não a da inclusão como paradigma hermenêutico dos direitos sociais.

Observa:

se os direitos sociais não se forjaram pela matriz do Estado liberal, mas do Estado Social; se não foram instituídos para ser desfrutados individualmente, mas pela sociedade como um todo; se não se constituem pela lógica da exclusão, mas da inclusão; se sua titularidade traduz-se em co-titularidade do igual direito dos demais indivíduos coimplicados na relação jurídica social, então a especificidade que a marca exigibilidade própria dos direitos sociais deve ter adequada tradução no plano processual.

Propõe, para isso, a hierarquização das tutelas voltadas à implementação dos direitos sociais, privilegiando-se a tutela coletiva face à individual, tida como meramente residual. 
Não se pretende com isto a denegação do acesso à justiça individual, o que além de ser inviável juridicamente em face do princípio constitucional da ação previsto no art. $5^{\circ}$, XXXV da Constituição da República, nenhum proveito traria à ampliação da eficácia dos direitos sociais. Porém, como se demonstrou, a residualidade da exigibilidade de um direito social manejada em ação individual deve ser restrita às hipóteses de ameaça ou lesão ao mínimo existencial, em que a atividade jurisdicional é necessária à preservação, manutenção ou reintegração da dignidade humana, justificando-se somente em tais casos. Logo, portanto, afora a ameaça ao mínimo existencial, a exigibilidade individual de um direito social deverá ser considerada desarrazoada.

É preciso evitar o impacto negativo que decisões isoladas possam causar na prestação de serviços públicos. É preciso evitar ou minimizar discrepâncias no critério de distribuição do serviço público, que ocorre quando uma decisão judicial privilegia um indivíduo (o que recorreu ao Judiciário) em relação aos que não participaram da demanda.

Afirma, em última análise, a necessidade de limites aos direitos sociais, quando pleiteados individualmente, (ainda que - acrescento - por ação coletiva relativa a direitos individuais homogêneos), a partir da constatação de que o plus reconhecido a implica um minus para todos os demais.

Sirva de exemplo caríssimo tratamento médico no exterior, concedido a um, cujo preço é subtraído às verbas destinadas aos demais. É preciso não esquecer que os valores arrecadados pelo Poder Público, e mesmo os arrecadáveis, sempre terão limites, motivo por que jamais será possível outorgar a todos direitos sociais infinitos.

A autora põe esse limite no "mínimo existencial". Proponho outra fórmula, a partir da distinção entre tutela de direitos coletivos e tutela, ainda que coletiva, de direitos individuais, distinção que envolve também uma diferença entre as funções que o Judiciário exerce nessas ações.

\section{CONCLUSÃO}

Políticas públicas podem ser fixadas em ações relativas a direitos difusos ou coletivos stricto sensu. Em ações, ainda que coletivas, relativas a direitos individuais, há de se observar os limites fixados por normas de políticas públicas.

A chamada reserva do possível tem lugar na determinação de políticas públicas e, portanto, em ações relativas a direitos difusos ou coletivos stricto sensu, jamais em ações individuais, fundadas em direitos subjetivos, no seu sentido clássico. É inadmissível que se negue um direito a pretexto de que o devedor não pode pagar. A execução pode até ser impossível, mas nem por isso pode ser negada a própria existência do direito subjetivo.

\section{REFERÊNCIAS}

LINS, Liana Cirne. A Tutela Inibitória Coletiva das Omissões Administrativas: um enfoque processual sobre a justiciabilidade dos direitos fundamentais sociais. Artigo publicado na Revista Direito do Estado $n^{\circ}$ 12, Rio de Janeiro: Renovar/Instituto Idéias, out-dez 2008, p. 223-261. 
NEDEL, José. A Ética da Responsabilidade de Hans Jonas. Revista da AJURIS, Porto Alegre, (82): t. I, p. 128-42, junho/2001.

ZAVASCKI, Teori Albino. Processo Coletivo - Tutela de Direitos Coletivos e Tutela Coletiva de Direitos. São Paulo: Revista dos Tribunais, 2006.

TJRGS, $3^{\text {a }}$ Câmara Cível, Apelação Cível 70020552246, Nelson Monteiro Pacheco, Relator, J. 4.06.2009.

TJRGS, 21 $1^{\text {a }}$ Câm. Cível, Apelação Cível 70029714060, Francisco José Moesch, Relator, J. 3.06.2009.

TJRGS, $3^{a}$ Câmara Cível, Apelação Cível 70025515628, Nelson Monteiro Pacheco, Relator, J. 28.05.2009.

TJRGS, $9^{a}$ Câmara Cível, Agravo de Instrumento 70029970928, Odone Sanguiné, Relator, J. 28.05.2009. 